\title{
COMPARATIVA DE LA COMPETENCIA MEDIÁTICA EN COMUNICACIÓN POLÍTICA VÍA TWITTER DURANTE LAS CAMPAÑAS ELECTORALES DE CANDIDATOS PRESIDENCIALES EN ESPAÑA, ECUADOR Y COLOMBIA
}

\author{
Manuel Antonio Conde del Río' \\ Universidad de Huelva, España / manuelantonioconde@gmail.com \\ Kevin Paúl Pullaguari-Zaruma² \\ Universidad Internacional de Andalucía, España / kppullaguari@hotmail.com \\ Oscar Andrés Prada-Espinel ${ }^{3}$ \\ Universidad Internacional de Andalucía, España / oprada9@gmail.com
}

Recibido: 19/2/2019/ Aceptado: 24/6/2019

doi: 10.26439/contratexto2019.n032.4606

Resumen. En la actualidad, es habitual la comunicación política desde las redes sociales, en especial vía Twitter. Con esta investigación hemos puesto de manifiesto las competencias mediáticas de 12 candidatos a la presidencia en España, Ecuador y Colombia, para lo cual escogimos a los cuatro principales líderes de cada país. Hemos realizado, con la herramienta de búsqueda avanzada de Twitter, la minería de datos, que arrojó un total de 3707 tuits enviados por dichos candidatos en sus campañas electorales, de los cuales 590 llevaban algún elemento audiovisual, 1743 incorporaban fotografías y 1174 contenían hashtags. Se eligió una investigación cuantitativa por su importancia para el análisis de los datos con un método flexible y de alcance exploratorio, ya que el tema no ha sido estudiado en profundidad anteriormente.

Palabras clave: competencia mediática / comunicación política / elecciones / redes sociales / Twitter

\footnotetext{
1 Máster en Comunicación y Educación Audiovisual por la Universidad de Huelva, España. https://orcid. org/0000-0002-7382-2166

2 Maestrando en Comunicación y Educación Audiovisual por la Universidad de Huelva, España. https:// orcid.org/0000-0001-6546-2618

3 Máster en Comunicación y Educación Audiovisual por la Universidad Internacional de Andalucía, España https://orcid.org/0000-0002-2974-9504
} 


\title{
A COMPARISON OF MEDIA COMPETENCY IN POLITICAL COMMUNICATION ON TWITTER AMONG PRESIDENTIAL CANDIDATES DURING THEIR ELECTION CAMPAIGNS IN SPAIN, ECUADOR AND COLOMBIA
}

\begin{abstract}
Currently, political communication is usual on social networks, especially on Twitter. This research has highlighted the media competencies of 12 presidential candidates in Spain, Ecuador and Colombia. To that end, the four main leaders of each country were chosen. Using Twitter's advanced search tool, data mining yielded a total of 3,707 tweets sent by these candidates during their election campaigns, out of which 590 had an audiovisual element, 1,743 had photographs and 1,174 used hashtags. A quantitative research was chosen due to its significance for data analysis with a flexible and exploratory method, since this subject has not been studied in depth before.
\end{abstract}

Keywords: Media competency / political communication / elections / social networks / Twitter

\section{UMA COMPARAÇ̃̃OO DA COMPETÊNCIA MIDIÁTICA NA COMUNICAÇÃO POLÍTICA NO TWITTER DE CANDIDATOS DURANTE AS CAMPANHAS ELEITORAIS PRESIDENCIAIS NA ESPANHA, NO EQUADOR E NA COLÔMBIA}

Resumo. Atualmente a comunicação política nas redes sociais é comum, principalmente no Twitter. Com esta pesquisa, revelamos as competências midiáticas de 12 candidatos à presidência em três países, Espanha, Equador e Colômbia e, para isso, foram escolhidos os quatro principais líderes de cada país. Com a ferramenta de pesquisa avançada do Twitter, realizamos a pesquisa de dados, a qual apresentou um total de 3707 tweets enviados pelos candidatos durante as campanhas eleitorais. Deles, 590 continham algum elemento audiovisual, 1743 inseriam fotografias e 1174 continham algum hashtags. Foi adotada uma pesquisa de caráter quantitativo devido à sua importância para a análise dos dados com um método flexível e de alcance exploratório, uma vez que esse tópico ainda não foi estudado a profundidade.

Palavras-chave: Competência midiática / comunicação política / eleições / redes sociais / Twitter 


\section{INTRODUCCIÓN}

Uno de los cambios que se evidencia en la coyuntura política es que el debate se ha trasladado de la plaza pública a las redes sociales, se pasó de la argumentación política estructurada y racional al enfoque en los sentimientos, por ello se considera pertinente comprender las nuevas dinámicas que permean la coyuntura política asociada con los nuevos canales de comunicación que ostenta la web 2.0 y 3.0.

Para la presente investigación se escogió a Colombia, Ecuador y España, porque, además de que son los países de origen de los investigadores y de que los precede una estrecha relación histórica, no hay un balance de poderes equitativo y el Ejecutivo prima sobre los demás. También se tuvo en cuenta que en estos países existe un cambio en las dinámicas de las corrientes político-ideológicas y ha habido corrupción político-electoral, que llevó a una polarización y al decaimiento de partidos políticos "fuertes", en gran medida por la cantidad de información que es expuesta diariamente en las redes sociales.

Se estableció como intervalo de estudio los 15 días previos a los comicios, ya que durante este periodo la contienda electoral se vuelve más agresiva y, por consiguiente, tiene más impacto para conseguir los resultados deseados dentro de este tipo de investigaciones sociopolíticas, teniendo en cuenta que el objetivo principal de este artículo es diagnosticar la comunicación política desde la perspectiva de la competencia mediática de los procesos comunicativos de las campañas electorales de España 2016, Ecuador 2017 y Colombia 2018.

\section{LA COMUNICACIÓN POLÍTICA}

La comunicación política es el espacio donde interactúan los discursos contradictorios de los tres actores legítimos que se expresan en público sobre política: los políticos, los periodistas y la opinión pública (Wolton, 1998). De igual manera, relaciona un conjunto de fenómenos comunicativos como la propaganda, el marketing político, el marketing electoral, relaciones públicas, políticas o comunicación institucional política, que implica un intercambio de mensajes y símbolos entre los participantes, lo que genera efectos en la política y lo político (Canel, 1999).

Según Norris (2004), las investigaciones referentes a la comunicación política la dividen en tres categorías principales, la producción, el contenido y los efectos. El proceso de producción se fundamenta en cómo los actores políticos generan el mensaje para transmitirlo a través de los canales directos, anuncios políticos, y canales indirectos, periódicos, radio, televisión y las herramientas que ofrece internet como las redes sociales. El contenido se refiere a los mensajes resultantes del proceso de producción. Y los efectos, son las consecuencias de la asimilación de los mensajes por parte de 
los receptores. Dichos efectos no solo se determinan por el contenido del mensaje, sino también por el contexto histórico en el que aparecen y, especialmente, el entorno político que prevalece en un momento dado (Mcnair, 2015).

En la comunicación política el contenido del mensaje se basa en la interpretación subjetiva que un ente político le atribuye a una problemática social, en lo que también juega un papel importante la cultura, en determinado contexto, así como el planteamiento de su posible solución, siempre y cuando dicha exégesis sea plausible.

Es pertinente afirmar que la comunicación política es un proceso cíclico en el que juega un papel determinante la opinión pública, generada por el debate de argumentos ciudadanos racionales que tienen como eje principal los intereses generales, el bien común y los problemas colectivos (Sartori, 1998). Por ello, los políticos generan mensajes vinculantes a los procesos identificatorios de ciertos grupos sociales, para identificar quiénes asimilan el contenido político-ideológico adherido a los mensajes de manera positiva y quiénes de manera negativa.

El papel fundamental de la comunicación política es convencer al mayor número de personas, para que legitimen el accionar político de ciertos grupos que son intrínsecos a esta disciplina. Sin embargo, en muchos casos el contenido discursivo está atiborrado de prejuicios y desinformación para apelar a los sentimientos de los receptores inconformes de diferentes situaciones propias de su contexto social y cultural, lo que convierte el discurso en un entramado demagógico que busca únicamente el empoderamiento del individuo o de determinados conglomerados económicos a los que representa, a través del control y la manipulación.

\section{LA COMUNICACIÓN POLÍTICA EN TWITTER}

Con el surgimiento y evolución de las TIC se generaron espacios digitales como las redes sociales, en las que los tres discursos planteados por Wolton, expuestos en el apartado anterior, participan e interactúan en igualdad de condiciones. Esto generó que los medios tradicionales, que presentaban la información únicamente de manera unidireccional, fueran desplazados gradualmente a un segundo plano como generadores de opinión pública; especialmente porque las generaciones más jóvenes demandan un mayor protagonismo a sus opiniones y nuevas formas de consumir y producir contenidos, dinámica bimodal que se conoce como prosumo. Esto obligó a los medios tradicionales, en muchos casos, a hibridarse con las prácticas, los géneros, las tecnologías y la temporalidad de los medios digitales, en los que las relaciones de poder entre los actores noticiosos están sometidas a continuas tensiones y cambios (Serrano-Puche, Fernández y Rodríguez-Virgili, 2018) que "impactaron fuertemente en el desarrollo de nuevas formas de expresión de la política" (Santander, Elórtegui, Ginzales, Allende-Cid y Palma, 2017, p. 43). 
A nivel macro, tres de los aspectos fundamentales y ventajas que las redes sociales han otorgado a la comunicación política, son: 1) no existe limitación en la temporalidad de emplazar un determinado contenido, se puede emitir a cualquier hora y en cualquier lugar, siempre y cuando exista conectividad a internet; 2) la conversación política en los medios digitales se inicia y sostiene más fácilmente que la conversación política cara a cara (Vaccari y Valeriani, 2018, p. 3); 3) la interacción es subsecuente al proceso de retroalimentación.

Twitter, al ser la más usada en el ámbito político-social, "se ha convertido en una moderna ágora de deliberación y confrontación de ideas y opiniones" (Cansino, Calles y Echeverría, 2016, p. 11), ya que reúne a ciudadanos dispuestos a discutir asuntos públicos y esto favorece la formación de la opinión pública sin necesidad de intermediarios y sin discriminación previa de los participantes (Moya y Herrera, 2015). Por ello, la estructura y la funcionalidad que posee Twitter lo convierten en un medio útil, ya que "pasó de ser un medio para informar a un medio que facilitó la conversación" (Moya y Herrera, 2015, p. 3). En consecuencia, la prensa, la radio y la televisión utilizan Twitter como un mecanismo para generar una mayor interacción y difusión de sus contenidos.

Lo mencionado permitió a la plataforma inducir una reconfiguración de la estructura de los discursos políticos hacia una ampliación del debate público mediante la facilitación de la conectividad social (Weller, Bruns, Burgess, Mahrt y Puschmann, 2014), porque "sirve como espacio para ejercer control, supervisión y crítica de las relaciones y constantes luchas en las que intervienen las instituciones gubernamentales, los actores políticos, las fuerzas de seguridad, la prensa y la ciudadanía, generando así un proceso sinérgico-retroalimentativo" (Prada-Espinel y Romero-Rodríquez, 2019), por lo que en muchos casos permite empoderamiento de los grupos de la sociedad civil y los activistas en comparación con las élites políticas y los medios tradicionales (Schünemann y Steiger, 2015).

Twitter se considera un medio idóneo para hacer proselitismo y acercarse al poder político, pues proporciona una plataforma tecnológica para que múltiples individuos crezcan como tendencias (Castells, 2015). Twitter puede intensificar el debate político pero igualmente entorpecerlo, a razón de la información fugaz e imprecisa, en ocasiones, resultante del bombardeo permanente de contenido al que está expuesto el usuario (Prada-Espinel y Romero-Rodríquez, 2019), lo que genera un mal uso de la plataforma, como expresar violencia verbal y difundir información falsa y rumores (Schreiner, 2018), y crea polarización o la acrecienta en caso de existir.

El alcance del poder político de Twitter es sui generis, pues permite crear redes porque es un instrumento de la web 2.0 y 3.0, y estas tienen características como la sindicación, la capacidad de crear hipervínculos y expandirse viralmente (Sala, 2016). Adicionalmente, la plataforma ejerce el papel de sonda que permite seguir y medir 
opiniones de manera continua durante extensos periodos (Santander et al., 2017), lo que la convierte en un almacenador de big data que se nutre de información sobre los sentimientos que los usuarios asocian a cierto tipo de contenidos (Martínez-Martínez y Lara-Navarra, 2014).

\section{LA ESTRATEGIA DE LA COMUNICACIÓN POLÍTICA EN TWITTER}

En muchos países el uso de Twitter ha sido adoptado por candidatos presidenciales como parte de la estrategia de su campaña política, para de esa manera llegar persuasivamente a los adultos jóvenes que dependen de los nuevos medios para socializar y participar políticamente (Towner y Munoz, 2016). En ese sentido, Twitter se está utilizando cada vez más dentro del dominio sociopolítico como un canal de circulación de información y opiniones, que ha contribuido a la edificación y masificación de las campañas electorales, cuyos triunfos han visto quienes han sacado provecho de ello (Ross y Rivers, 2018).

Twitter, por su naturaleza de comunicación directa en tiempo real, se ha vuelto implacable en este tipo de eventos ante las demás redes, indica Conway, Kenski y Wang (2015): "Hoy en día, Twitter se está adoptando como un nuevo podio político para difundir información a una audiencia cada vez mayor" (p. 365) e incluso puede llegar a predecir las elecciones presidenciales (Budiharto y Meiliana, 2018). Twitter, por su estructura narrativa e interactiva, facilita la comunicación entre sus usuarios, pues es una red social abierta que se caracteriza por lo simple en la creación de contenidos multimedia y sirve para simpatizar con partidos políticos y ciudadanía (Pérez-Martínez, Rodríguez González y Tobajas Gracia, 2017).

La estrategia de comunicación política electoral en Twitter es en doble escala; en primer lugar, mediante su funcionalidad dentro de los 280 caracteres, más una imagen multimedia o link, produciendo comentarios, retuits e incluso campañas a favor y, por supuesto, dirigiéndose a una audiencia más amplia y heterogénea; en segundo lugar, los medios tradicionales se ocupan de llevar la noticia publicada a sus pantallas (RodríguezAndrés, 2018), lo que permite ahorro de tiempo y dinero. Algunos candidatos explotan sus funciones interactivas, pero muchos optan por utilizar Twitter como un medio de transmisión en lugar de un espacio de debate con los votantes (Hemsley, Stromer-Galley, Semaan, y Tanupabrungsun, 2018), y por ello la funcionalidad de comunicación política que brinda Twitter es diferente en el mundo de las redes sociales por el hecho de que la mayoría de sus mensajes son públicos, cortos y gran parte de ellos son abiertos al examen de cualquier persona conectada diariamente, a diferencia de Facebook o Google+, por ejemplo, en que el contenido es generalmente más restringido a audiencias específicas (Ituassu, Lifschitz, Capone, Vaz, y Mannheimer, 2018). 


\section{GENERACIÓN DE CONTENIDO: TRÁFICO, SEGUIDORES Y POSIBLES VOTANTES}

La tecnología evoluciona constantemente, por lo que las redes se han convertido hoy en elementos fundamentales para las campañas políticas (Towner y Dulio, 2012), por su don de producir contenido en tiempo real. En ese sentido, Twitter juega un rol preponderante en la concatenación de los candidatos presidenciales con los posibles votantes. Estos medios permiten a los usuarios publicar información dirigida (Oselio y Hero, 2016) e interactuar con los demás, ya sea de uno a uno o en grupos (Baumgartner y Morris, 2010). En esa tónica, estos sitios crean vínculos directos entre el público, gobierno y medios tradicionales (Johnson y Kaye, 2015), que se convierten en el tráfico y los seguidores que los candidatos buscan.

La generación de contenido repercute en la creación de tráfico; quien crea contenido obtiene seguidores, que se convertirán en posibles votantes; en otras palabras, el alcance de los mensajes difundidos por Twitter promueve el éxito de las campañas en dicha red (El Tantawi, Al-Ansari, AlSubaie, Fathy, Aly y Mohamed, 2018), ya que los contenidos tienden a influir en el conocimiento de los ciudadanos sobre cuestiones políticas (Dimitrova, Shehata, Strömbäck y Nord, 2014) al reconfigurar aspectos de la organización política, el discurso y el compromiso, que van desde me gusta, retuits, acciones, interacciones, memes, entre otros. Asimismo, los usuarios tienen una voz amplificada en la esfera pública y política en línea (Eddington, 2018).

La generación de contenido se puede utilizar para comprender cómo los diferentes actores de los partidos políticos se involucran en el juego electoral en Twitter para acarrear tráfico, ganar seguidores y así posibles votantes (Sun, Ch'ng y See, 2018). Para ello, Fung, Jackson, Mullican, Blankenship, Golf, Guinn y Tse (2018) realizaron un estudio de caso en el cual comprobaron que adjuntar pistas visuales a los tuits aumentará su frecuencia de retuiteo y esta práctica puede mejorar el compromiso de los usuarios de Twitter con los mensajes para una mejor comunicación política mediante la generación de contenido.

La generación de contenido de los políticos ha hecho que la premisa de todos los resultados beneficiosos sea una gran cantidad de seguidores digitales que reaccionan activamente a los mensajes públicos de los políticos, "los tuits publicados por los candidatos presidenciales revelan sus posiciones políticas en varias dimensiones y que los partidarios revelan su preferencia política al decidir si les 'gustan' los tuits o no" (Wang, Feng, Zhang y Luo, 2017 p. 5). Asimismo, el éxito de la comunicación de los actores políticos en las redes debe definirse como su capacidad para construir una gran cantidad de tráfico-seguidores y desencadenar tantas reacciones de sus seguidores como sea posible, a tal punto de afianzar votos a su favor (Keller y Kleinen-von Königslöw, 2018). 


\section{REGULACIÓN DE LOS PROCESOS ELECTORALES EN ESPAÑA, ECUADOR Y COLOMBIA}

En las constituciones de los tres países se regula por parte del Legislativo las formas de elegir a los presidentes de Gobierno; en España en la Constitución de 1978 (BOE, 1978), en Ecuador en la Constitución del 2008 (Asamblea Constituyente, 2008) y en Colombia en la Constitución Política de 1991 (Corte Constitucional, 1991). Aunque de una forma más detallada estos procesos se regulan en los textos legislativos que provienen de las distintas constituciones, en España, la Ley Orgánica 5/1985, del 19 de junio, del Régimen Electoral General (BOE, 1985); en Ecuador, en la Ley Orgánica Electoral. Código de la Democracia de 2009 (Asamblea Constituyente, 2009); y en Colombia, en el Decreto 2241 de 15 de julio de 1986. Código Electoral Colombiano (Registraduría Nacional del Estado Civil, 1986).

En cuanto al derecho de participación, el artículo 23 de la Constitución española dice textualmente: "Los ciudadanos tienen el derecho a participar en los asuntos públicos, directamente o por medio de representantes, libremente elegidos en elecciones periódicas por sufragio universal". Es importante destacar este artículo de la Constitución pues de él emana un derecho fundamental para toda la ciudadanía y que es el inicio de todos los procesos electorales que se desarrollen bajo este marco constitucional (BOE, 1978).

La elección del presidente del Gobierno en España no es por elección directa como en Ecuador y Colombia; en España la elección es a propuesta del rey. Una vez consultados los representantes designados por los grupos políticos que han obtenido representación parlamentaria en las elecciones generales, el rey propone al candidato a la presidencia, a través del presidente del Congreso. El candidato propuesto expone ante el Congreso de los Diputados su programa político de gobierno y solicita la confianza de la cámara. Si este obtiene la mayoría absoluta en la primera votación o la mayoría simple en una segunda votación, según el artículo 99 de la Constitución española, recae en la figura del rey su nombramiento, como se establece en el artículo 62. Una vez elegido y nombrado por el Parlamento y el rey, el presidente dirigirá la acción del Gobierno y coordinará las funciones de los demás miembros del mismo (BOE, 1978).

En España el Ministerio del Interior es el que gestiona todos los datos de los procesos electorales en la red. Se publican en su sitio web de forma pública las candidaturas que se presentan, las mesas de votaciones y finalmente los resultados finales de los procesos electorales (Ministerio del Interior. Gobierno de España, 2016).

Los derechos de participación en la Constitución de Ecuador son recogidos en el Capítulo Quinto: Derechos de Participación. En su artículo 61.1, sobre el derecho de elegir y ser elegidos, ya establece de forma general uno de los derechos fundamentales para la participación de la ciudadanía en la construcción política del país. 
El presidente de la República en Ecuador ejerce las funciones de jefe del Estado y de Gobierno, según el artículo 141 de la Constitución. Es elegido, junto con el vicepresidente de la República, mediante elecciones presidenciales, en las que debe obtener la mayoría absoluta de los votos. Si no fuese así, se realizaría una segunda vuelta electoral dentro de los 45 días en la que participarían los dos candidatos con mejores resultados en la primera vuelta. Esta elección será para un periodo de cuatro años, según los artículos 143-144 de la Constitución (Asamblea Constituyente, 2008).

El desarrollo de los procesos electorales lo norma la Ley 2, Registro Oficial Suplemento 578 del 17 de abril del 2009 (Asamblea Constituyente, 2009), que emana del artículo 217 de la Constitución, el cual establece que la función electoral estará conformada por el Consejo Nacional Electoral y el Tribunal Contencioso Electoral, en la sección primera del Capítulo Sexto. Es decir, la elección de presidente, como ya indicamos anteriormente, es distinta que en España, pues en Ecuador es por votación directa.

Todo el proceso de elecciones es publicado por el Consejo Nacional Electoral en su sitio web: normas electorales, plan de seguimiento, organizaciones políticas que concurren, circunscripciones electorales, hasta llegar a los resultados electorales finales (Consejo Nacional Electoral. Ecuador, 2017).

En la Constitución de Colombia, su artículo 40 establece el derecho de participación de la ciudadanía para el ejercicio y control del poder político en el país. Para ello desarrolla, mediante la redacción de siete puntos, todo lo que representa ese derecho para la ciudadanía colombiana (Corte Constitucional. Gobierno de Colombia, 1991). Destaca el punto 2, "Tomar parte en las elecciones, plebiscitos, referendos, consultas populares y otra forma de participación democrática", que, en definitiva, supone la base del sufragio universal para todos los colombianos.

De acuerdo con la Constitución de Colombia, el presidente de la República es el jefe de Estado y de Gobierno y suprema autoridad administrativa, según el artículo 115. Es elegido mediante sufragio directo para un periodo de cuatro años junto con el vicepresidente, para lo cual tiene que obtener, en una primera votación, la mayoría de los votos. En el caso de no lograr dicha mayoría, se celebraría una segunda votación en la que solo participarían los dos candidatos con mayor número de votos. De esa votación será declarado presidente quien obtenga el mayor número de votos, conforme lo establece el artículo 190 de la Constitución (Corte Constitucional. Gobierno de Colombia, 1991).

Según establece el artículo 120 de la Constitución, "La organización electoral está formada por el Consejo Nacional Electoral, por la Registraduría Nacional del Estado Civil y por los demás organismos que establezca la Ley". Los resultados de los procesos electorales en Colombia son tramitados por el Consejo Nacional Electoral y, con el objeto de asumir conceptos de transparencia política, publicados en su sitio web (Consejo Nacional Electoral, Colombia, 2018). 


\section{LA COMPETENCIA MEDIÁTICA}

Para Manrique-Grisales, Romero y Fernández (2017), la competencia mediática no debe entenderse únicamente como el desarrollo de la capacidad humana de recibir y producir información, más bien como un armazón en el que convergen la comunicación, la educación y la cultura. De igual modo, se puede decir que es aquella que permite al ciudadano ser activo, crítico y responsable en el entorno complejo: digital, multimediático y en constante cambio. Esto no solo permitirá entender la evolución y el impacto de la competencia mediática en sí, sino también al Estado en el ecosistema mediático que es donde se gestan las relaciones del mundo contemporáneo. Gracias a ello se podrá lograr un empoderamiento ciudadano, una mejora en sus vidas y "minimizar la brecha digital existente en diversos colectivos vulnerables o en riesgo de exclusión" (García-Ruiz, Gozálvez y Aguaded, 2014, p. 16)

En la competencia mediática existe un trinomio que es su base y su fin último, este es educación-comunicación-cultura, ligado a los avances tecnológicos. Esta relación, para los autores Narváez-Montoya y Romero-Peña (2017), desemboca en al menos dos versiones, una llamada convencional o institucional, en la que se establece una diferencia entre comunicación y medios; y la versión tecnológica o comunicación educativa que, grosso modo, pretende que la institución mediática cumpla el papel de las otras instituciones. En otras palabras, que los medios sean los transmisores de los saberes disciplinares, estéticos y culturales.

En Colombia existen tres órganos para cada parte que compone el trinomio (educación-comunicación-cultura): el Ministerio de Educación, el Ministerio de las TIC y el Ministerio de Cultura. Cada uno regula una institución social que desempeña funciones en nombre de la sociedad: la escuela, los medios y tecnologías, y las instituciones artísticas y patrimoniales (Narváez-Montoya y Romero-Peña, 2017). En Ecuador, la Constitución del 2008 propone en el apartado Buen Vivir, artículo 347, numeral 8, que es responsabilidad del Estado "incorporar las tecnologías de la información y comunicación en el proceso educativo y propiciar el enlace de la enseñanza con las actividades productivas o sociales" (Asamblea Constituyente, 2008). Así también, en el artículo 35 de la Ley Orgánica de Comunicación, sobre el derecho al acceso universal a las tecnologías de la información y de la comunicación, precisa: "Todas las personas tienen derecho a acceder, capacitarse y usar las tecnologías de información y comunicación para potenciar el disfrute de sus derechos y oportunidades de desarrollo" (Asamblea Constituyente, 2013). En este contexto, en el 2002 empieza la iniciativa de incorporar las TIC y es a partir de ahí que desarrollan programas para fortalecer el aprendizaje en el uso de estas (Peñaherrera León, 2012). Por tanto, podemos constatar que Ecuador también se encuentra inmerso en el desarrollo mediático de su sociedad y, como consecuencia, sus escuelas buscan estar dotadas para acoplarse al uso de las TIC (Marín-Gutiérrez, DíazPareja y Aguaded, 2013). 
Solo será posible alcanzar una óptima competencia mediática a través de la alfabetización mediática, que, para la European Commission (2019), es la capacidad de acceso, consulta, comprensión, creación y la evaluación crítica de los diferentes medios de comunicación como también de sus contenidos. Por ello, desde una perspectiva de cambio social, la alfabetización mediática tiene por foco los medios participativos, lo que resulta ser una respuesta activa a las luchas que el poder económico y político no han resuelto en el marco de la esfera mediática, y brinda la posibilidad de que los jóvenes tengan voz ante situaciones y puedan configurar el contexto en que viven (Rheingold, 2008).

De los tres países, España encabeza la lista en materia de competencias y alfabetización mediática, le siguen Ecuador y Colombia. Autores como Marín-Gutiérrez et al. (2013) destacan la participación del Estado ecuatoriano en la integración de las TIC en la educación y sociedad, ya que existe un número importante de proyectos con respecto a la competencia mediática, aunque para otros investigadores esto va más en función y ánimo de los docentes-académicos. Indican que las TIC están generando un enorme interés en el país, pero también admiten que los continuos cambios de gobierno han complicado la continuidad del proceso de implementación. Otros académicos argumentan que no existen políticas claras o definidas a pesar de que en los últimos años en los estados americanos se ha visto la necesidad de formular políticas públicas para reducir este déficit y promover así la creación de sociedades de la información (Guerra y Jordán, 2010). En el caso de Colombia, la falencia de la competencia mediática está permeada por los constantes recortes y desviación de recursos para la educación, la polarización extremista presente en la sociedad, los partidos políticos y algunos medios de comunicación, y la poca investigación en territorio colombiano sobre estos temas.

\section{METODOLOGÍA}

Inicialmente identificado el problema por investigar, se consideró como metodología para este trabajo un diseño cuantitativo. Según Hernández, Fernández y Baptista (2014), "el enfoque cuantitativo parte de que el mundo social es intrínsecamente cognoscible y todos podemos estar de acuerdo con la naturaleza de la realidad social" (p. 6). Además, plantean que los datos observados y medidos por medio de este enfoque no deben ser manipulados por los autores. De igual forma se pretende generalizar, constatar, confirmar y predecir los resultados de un intervalo, mediante pruebas, para acotar la información. Asimismo se utilizó la técnica de análisis de contenido para estudiar la competencia mediática en la comunicación política, ya que es idónea para "estudiar cualquier tipo de comunicación de una manera 'objetiva' y sistemática, que cuantifica los mensajes o contenidos en categorías y subcategorías, y los somete a análisis estadístico" (Hernández et al., 2014, p. 251). 
Al respecto, Ferrés y Piscitelli (2012) también hacen eco del análisis de la competencia mediática de los candidatos y agregan que existen seis dimensiones que la conforman: lenguajes, tecnología, procesos de interacción, procesos de producción y difusión, ideología y valores, y estética. Estas dimensiones y sus ámbitos son los indicativos que nos ayudan a comprender cómo los usuarios de Twitter reciben los mensajes y cómo interaccionan con ellos, y cómo los candidatos que producen los mensajes hacen un uso adecuado de sus competencias mediáticas.

Con el objeto de recopilar datos objetivos y suficientes para realizar la investigación, utilizamos un muestreo no probabilístico que permitió seleccionar una muestra de la población accesible y centrada en el tema de estudio. Se seleccionaron 4 candidatos a las elecciones presidenciales de cada uno de los países escogidos (España, Ecuador y Colombia), para contar con un total de 12. La franja del estudio se estableció en los 15 días previos a los comicios. Cabe acotar que dichos datos fueron recopilados manualmente, pues no se encontró ningún software confiable para su recolección, ya que presentaban desfases en la información en los tuits de un día a otro. Posteriormente, se diseñaron unas rejillas de análisis de los mensajes para cada uno de los candidatos.

\section{RESULTADOS}

Para el análisis de los datos obtenidos a través de la búsqueda avanzada de Twitter, establecimos una serie de tablas con los datos totales y los datos desagregados de cada uno de los países. Se estudiaron los cuatro líderes de los tres países establecidos con mayores opciones para llegar a la presidencia y, por consiguiente, los más votados en los procesos electorales.

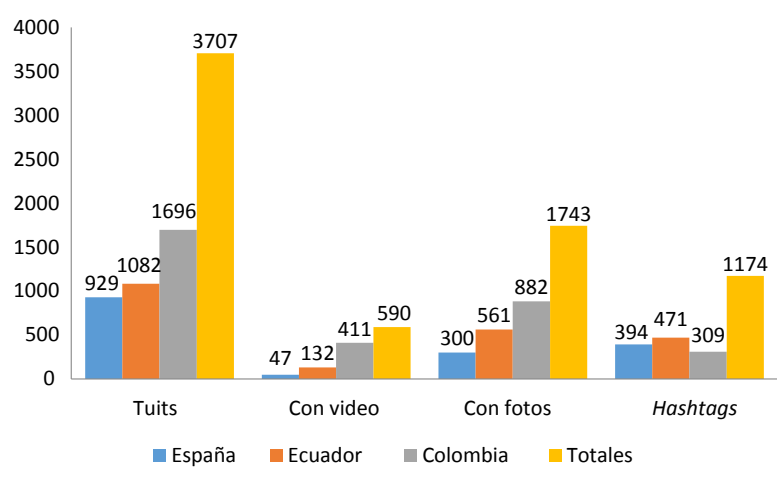

Figura 1. Tuits analizados para cada país

Elaboración propia 
Para la selección de los tuits de la muestra, se realizaron diversos filtros de búsqueda avanzada de Twitter correspondientes a la franja de tiempo analizada en cada uno de los procesos, que acordamos que fuesen los 15 días anteriores a la fecha de la celebración de los comicios. Esto arrojó un total de 3707 tuits para analizar (590 tenían video; 1743, elementos gráficos; y del total, 1174 contenían hashtags). Salvo el caso de los candidatos colombianos, cuyo número de tuits se sitúa en 1696, las cifras de los candidatos españoles y ecuatorianos son muy similares. El uso de videos está mucho más extendido entre los candidatos colombianos, que los han utilizado de forma masiva. Sin embargo, son los candidatos ecuatorianos los que hicieron un uso más significativo de los hashtags en sus publicaciones.

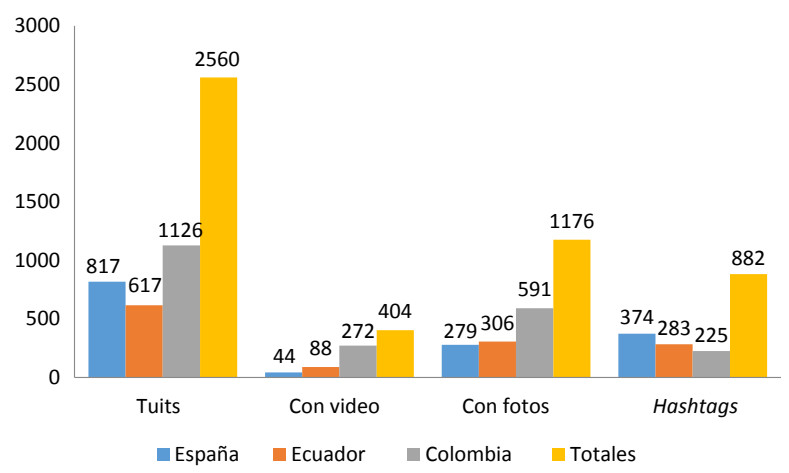

Figura 2. Tuits publicados antes de la primera vuelta

Elaboración propia

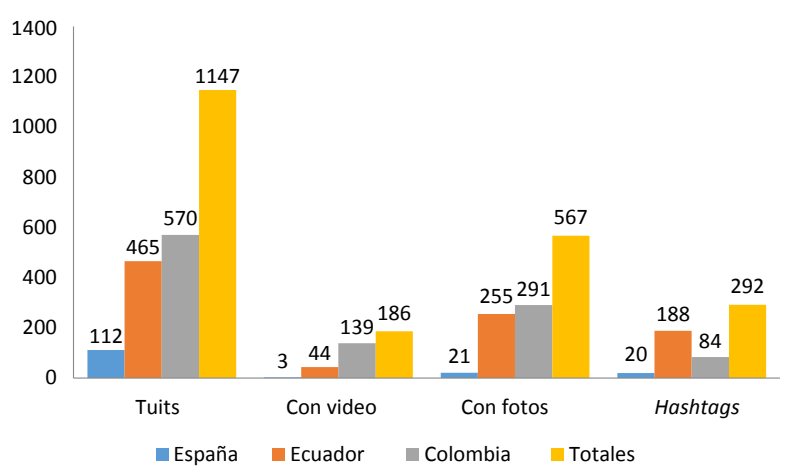

Figura 3. Tuits publicados durante la segunda vuelta

Elaboración propia 
Durante la campaña electoral previa a la primera vuelta, como se denomina el día de los comicios en Ecuador y Colombia, los candidatos colombianos son los más activos en Twitter y los que hacen un uso mayor de medios audiovisuales y gráficos. Sin embargo, durante el intervalo escogido los candidatos españoles son los que más utilizan hashtags para enlazar sus publicaciones en la red social.

Antes de la segunda vuelta en Ecuador y Colombia, y en el proceso electoral en España, observamos cómo los candidatos colombianos se mantienen como los más activos en Twitter.

\section{DATOS Y ANÁLISIS DE LOS CANDIDATOS ESPAÑOLES}

Comenzando con la desagregación de datos por países y candidatos, vemos en primer lugar los del proceso electoral en España del 26 de junio del 2016.

Hemos elegido las cuentas de los cuatro principales candidatos a la Presidencia del Gobierno: la del expresidente Mariano Rajoy, con un total de 1,62 millones de seguidores; la del líder de la oposición Pedro Sánchez, con 981 mil seguidores; la de Albert Rivera, con un total de 1,1 millones de seguidores; y por último, Pablo Iglesias, con 2,25 millones de seguidores, el cual es uno de los políticos con más seguidores en la red social.

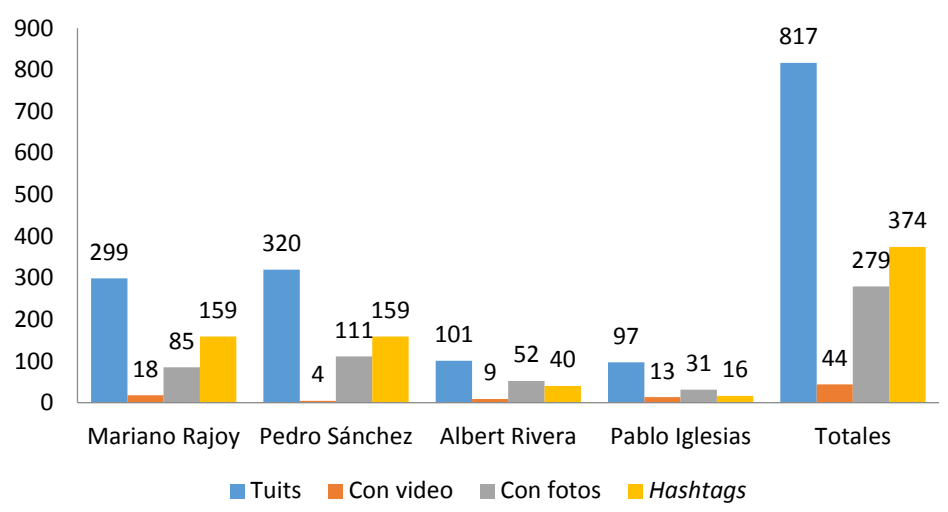

Figura 4. Tuits publicados durante las elecciones generales del 2016 en España (del 10 al 26 de junio)

Elaboración propia

El periodo analizado fue del 10 al 26 de junio, establecido según la normativa electoral como campaña. En la figura 4 se observan los candidatos estudiados de las cuatro fuerzas políticas con más votos al finalizar el proceso electoral, con un total de 817 
publicaciones, que contaban con 44 videos, 279 fotografías y 374 hashtags. Se evidencia que los dos candidatos que obtuvieron la mayoría de votos son quienes tuvieron una acción más intensa en Twitter. Cabe destacar el poco uso de elementos audiovisuales por casi todos los candidatos, especialmente el candidato @sanchezcastejon, que tan solo utiliza 4 durante el intervalo escogido de la campaña electoral. El número de hashtags entre los dos primeros candidatos es igual. Nuevamente vemos cómo los otros dos candidatos hicieron un uso mucho más bajo de todos los elementos de acompañamiento de sus publicaciones en la red social.

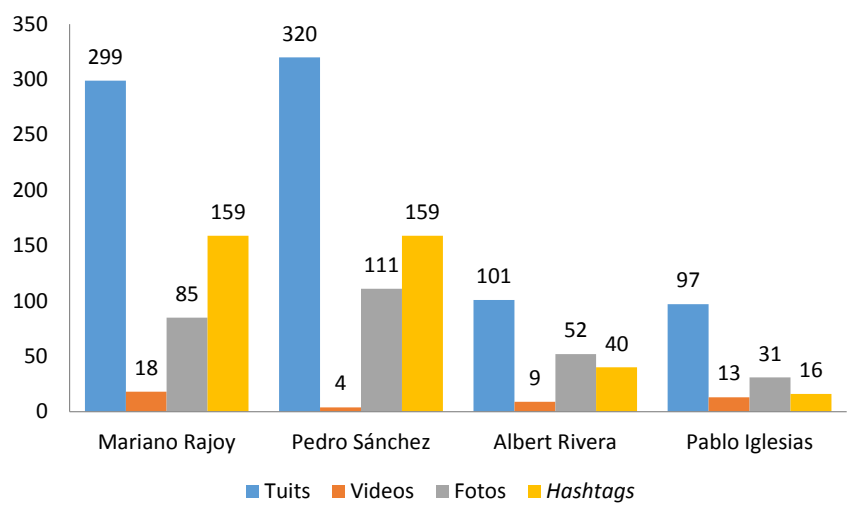

Figura 5. Actividad total en Twitter de los candidatos españoles en las elecciones generales del 2016

Elaboración propia

La tabla 1 refleja la actividad diaria de los candidatos y destaca la regularidad de sus publicaciones. Los dos primeros son los que más tuits poseen, pero guardan una media normalizada en sus publicaciones sin que tengan ningún día destacable que salga de la línea de publicación. Podemos destacar que para todos los candidatos los dos primeros días son cuando menos publicaciones tienen y los días oficiales de campaña cuando más activos están en la red. En España existe un día de reflexión antes de las votaciones y se aprecia cómo baja de forma importante el número de publicaciones ese día y el de los comicios.

Como hemos indicado anteriormente, no hay elección directa del presidente de España, sino que esa prerrogativa legal pertenece al Congreso de los Diputados a propuesta del rey del Reino de España, por lo que no existe una segunda vuelta, sino que interviene el Parlamento. En este proceso electoral, demoró el nombramiento del presidente por la falta de acuerdos de los grupos políticos. El 30 de octubre Mariano Rajoy fue nombrado presidente. 


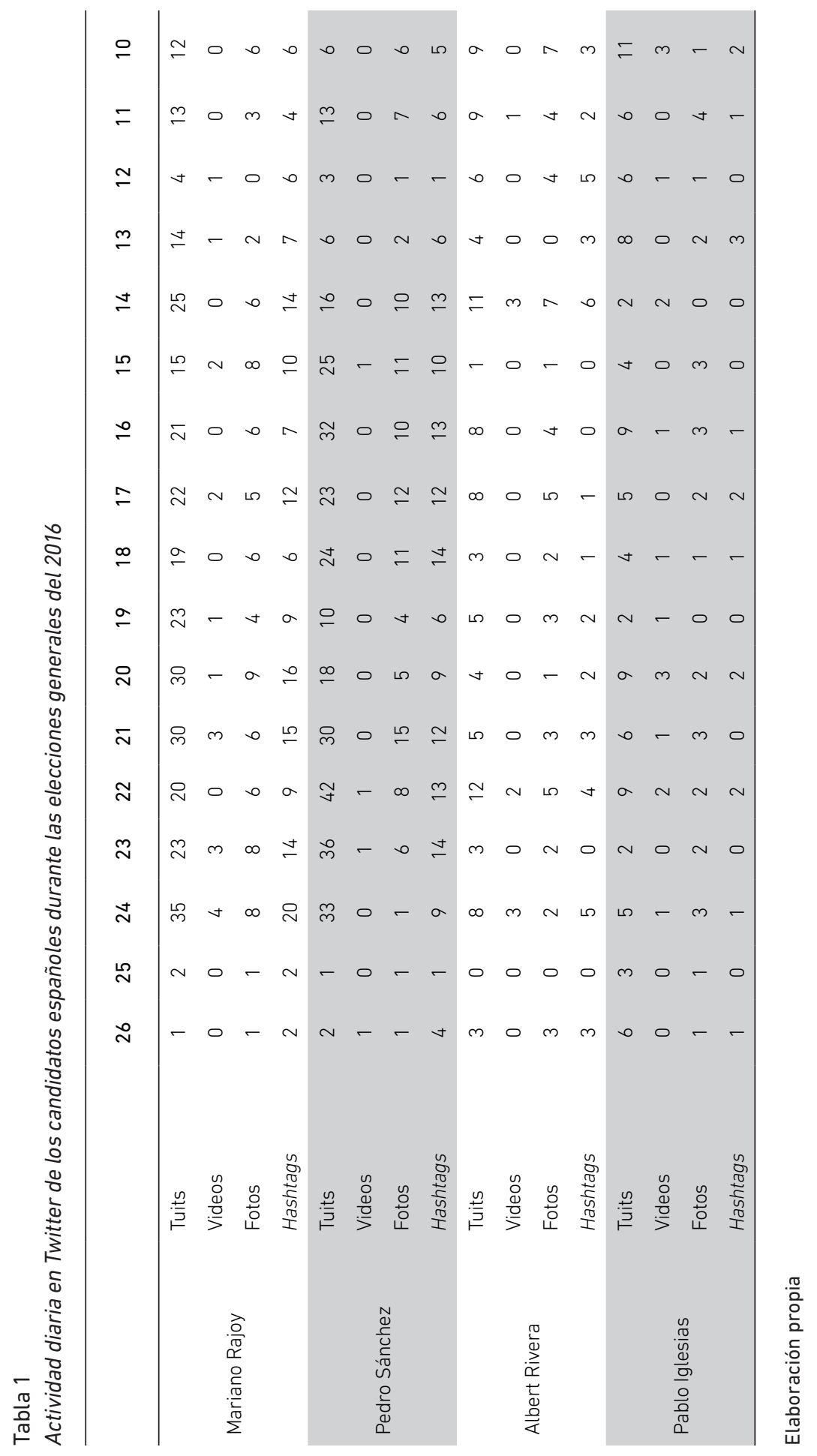


Tabla 2

Actividad en Twitter del candidato Mariano Rajoy y desglose por día del 15 al 30 de octubre

\begin{tabular}{lccccccccccccccccc}
\hline $\begin{array}{l}\text { Mariano } \\
\text { Rajoy }\end{array}$ & 30 & 29 & 28 & 27 & 26 & 25 & 24 & 23 & 22 & 21 & 20 & 19 & 18 & 17 & 16 & 15 & TOTAL \\
\hline Tuits & 0 & 17 & 2 & 22 & 33 & 6 & 11 & 0 & 0 & 5 & 1 & 1 & 1 & 10 & 2 & 1 & 112 \\
Vídeos & 0 & 1 & 0 & 0 & 0 & 1 & 0 & 0 & 0 & 0 & 1 & 0 & 0 & 0 & 0 & 0 & 3 \\
Fotos & 0 & 7 & 1 & 2 & 5 & 0 & 1 & 0 & 0 & 0 & 0 & 1 & 0 & 3 & 1 & 0 & 21 \\
Hashtags & 0 & 3 & 2 & 2 & 1 & 0 & 5 & 0 & 0 & 2 & 0 & 1 & 1 & 2 & 0 & 1 & 20 \\
\hline
\end{tabular}

Elaboración propia

Se evidencia que la actividad del candidato a asumir la Presidencia del Gobierno en España decae mucho en comparación con la campaña electoral y nuevamente se colige el poco uso de medios audiovisuales y gráficos en sus publicaciones. Aquí se añade un nuevo elemento para tener presente, que es la poca regularidad en la publicación de tuit. Se observa que hubo días con pocas o nulas publicaciones.

\section{DATOS Y ANÁLISIS DE LOS CANDIDATOS ECUATORIANOS}

En el caso de Ecuador también seleccionamos a los cuatro principales candidatos a la Presidencia del Gobierno de la República: la cuenta de Lenín Moreno, con un total de 667 mil seguidores; la de Guillermo Lasso, con 518 mil seguidores; la de Cynthia Viteri, con 262 mil seguidores; y por último la de Paco Moncayo, con 1817 seguidores.

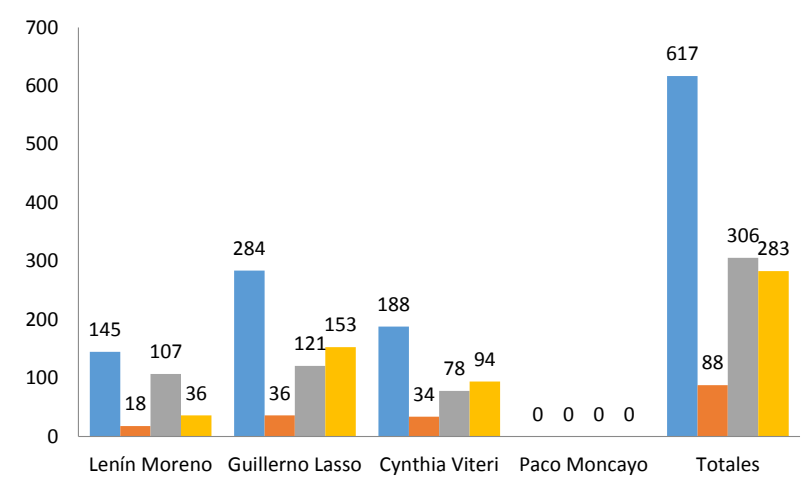

Figura 6. Tuits publicados durante las elecciones presidenciales del 2017 en Ecuador (primera vuelta). Del 4 al 19 de febrero del 2017 Elaboración propia 
El periodo analizado fue del 4 al 19 de febrero del 2017, intervalo establecido de la campaña previa al proceso electoral. En la figura 6 observamos que entre los tres primeros candidatos las cifras son similares y que todos guardan mucha similitud en su forma de uso de Twitter. Llama la atención que el cuarto candidato no hizo en ningún momento uso de Twitter a pesar de tener más de 1817 seguidores. El candidato más activo de todos fue @LassoGuillermo.

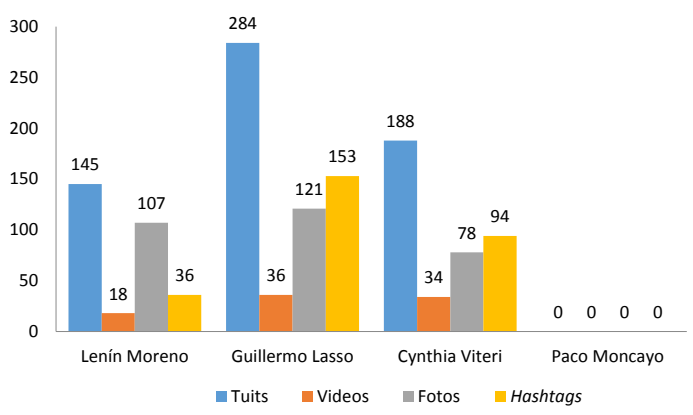

Figura 7. Actividad total en Twitter de los candidatos ecuatorianos durante las elecciones presidenciales del 2017 (primera vuelta)

Elaboración propia

Tabla 3

Actividad diaria en Twitter de los candidatos ecuatorianos durante las elecciones presidenciales del 2017 (primera vuelta)

\begin{tabular}{|c|c|c|c|c|c|c|c|c|c|c|c|c|c|c|c|c|c|}
\hline & & 19 & 18 & 17 & 16 & 15 & 14 & 13 & 12 & 11 & 10 & 9 & 8 & 7 & 6 & 5 & 4 \\
\hline \multirow{4}{*}{ Lenín Moreno } & Tuits & 3 & 4 & 18 & 8 & 14 & 7 & 11 & 1 & 9 & 14 & 5 & 12 & 12 & 1 & 19 & 7 \\
\hline & Videos & 0 & 0 & 1 & 2 & 2 & 1 & 2 & 1 & 0 & 3 & 0 & 5 & 0 & 1 & 0 & 0 \\
\hline & Fotos & 3 & 4 & 17 & 6 & 12 & 6 & 10 & 0 & 9 & 11 & 5 & 6 & 10 & 0 & 1 & 7 \\
\hline & Hashtags & 0 & 0 & 0 & 3 & 2 & 1 & 1 & 0 & 0 & 2 & 0 & 8 & 0 & 1 & 16 & 2 \\
\hline \multirow{4}{*}{ Guillermo Lasso } & Tuits & 38 & 1 & 4 & 37 & 29 & 18 & 16 & 10 & 5 & 14 & 7 & 28 & 31 & 7 & 32 & 7 \\
\hline & Videos & 3 & 1 & 4 & 1 & 2 & 2 & 2 & 2 & 1 & 3 & 0 & 4 & 2 & 2 & 2 & 5 \\
\hline & Fotos & 6 & 0 & 0 & 22 & 16 & 6 & 13 & 2 & 4 & 9 & 7 & 17 & 6 & 4 & 7 & 2 \\
\hline & Hashtags & 20 & 0 & 2 & 22 & 11 & 11 & 12 & 3 & 4 & 8 & 6 & 6 & 8 & 4 & 22 & 6 \\
\hline \multirow{4}{*}{ Cynthia Viteri } & Tuits & 17 & 0 & 4 & 13 & 4 & 10 & 5 & 7 & 3 & 7 & 9 & 17 & 37 & 17 & 31 & 7 \\
\hline & Videos & 7 & 0 & 3 & 6 & 1 & 2 & 1 & 1 & 1 & 1 & 3 & 1 & 3 & 2 & 0 & 2 \\
\hline & Fotos & 6 & 0 & 1 & 7 & 3 & 7 & 4 & 5 & 1 & 5 & 5 & 8 & 3 & 8 & 12 & 3 \\
\hline & Hashtags & 10 & 0 & 2 & 13 & 3 & 5 & 2 & 4 & 2 & 5 & 7 & 9 & 9 & 4 & 15 & 4 \\
\hline \multirow{4}{*}{ Paco Moncayo } & Tuits & 0 & 0 & 0 & 0 & 0 & 0 & 0 & 0 & 0 & 0 & 0 & 0 & 0 & 0 & 0 & 0 \\
\hline & Videos & 0 & 0 & 0 & 0 & 0 & 0 & 0 & 0 & 0 & 0 & 0 & 0 & 0 & 0 & 0 & 0 \\
\hline & Fotos & 0 & 0 & 0 & 0 & 0 & 0 & 0 & 0 & 0 & 0 & 0 & 0 & 0 & 0 & 0 & 0 \\
\hline & Hashtags & 0 & 0 & 0 & 0 & 0 & 0 & 0 & 0 & 0 & 0 & 0 & 0 & 0 & 0 & 0 & 0 \\
\hline
\end{tabular}

Elaboración propia 
La tabla 3 evidencia la actividad diaria de los cuatro candidatos. En los tres primeros destaca la regularidad en sus publicaciones durante el intervalo establecido, aunque se observa que @Lenin tiene algunos días en que baja su número de publicaciones drásticamente.

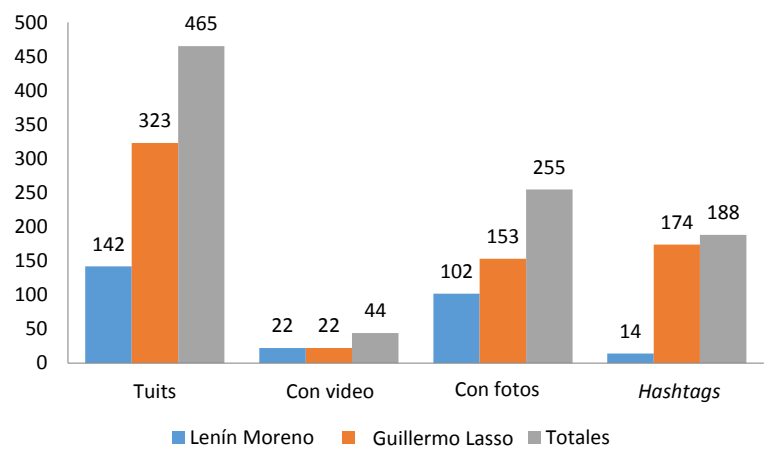

Figura 8. Tuits publicados durante las elecciones presidenciales del 2017 en Ecuador (segunda vuelta). Del 18 de marzo al 2 de abril del 2017 Elaboración propia

Ninguno de los candidatos obtuvo una mayoría simple, por lo cual se estableció una segunda vuelta electoral con los dos mejor situados. Para la minería se estableció el periodo comprendido entre el 18 de marzo y el 2 de abril del 2017, con un total de 465 tuits entre los dos candidatos, que incluían 44 videos y 255 fotografías. Nuevamente utilizaron hashtags, aunque el uso fue desigual.

Tabla 4

Actividad en Twitter de los candidatos ecuatorianos durante las elecciones presidenciales del 2017 (segunda vuelta)

\begin{tabular}{|c|c|c|c|c|c|c|c|c|c|c|c|c|c|c|c|c|c|c|}
\hline & & 2 & 1 & 31 & 30 & 29 & 28 & 27 & 26 & 25 & 24 & 23 & 22 & 21 & 20 & 19 & 18 & Total \\
\hline \multirow{4}{*}{$\begin{array}{l}\text { Lenín } \\
\text { Moreno }\end{array}$} & Tuits & 9 & 0 & 0 & 13 & J & 14 & 9 & 3 & 3 & 10 & 10 & 12 & 13 & 6 & 4 & 12 & 142 \\
\hline & Videos & 0 & 2 & 1 & 1 & U & 4 & 0 & 2 & 1 & 4 & 1 & 4 & 2 & 0 & 0 & 0 & 22 \\
\hline & Fotos & 8 & 5 & 5 & 8 & 5 & 9 & 9 & 3 & 2 & 4 & 11 & 7 & 7 & 6 & 4 & 9 & 102 \\
\hline & Hasht & 1 & 6 & 0 & 0 & 0 & 0 & 0 & 0 & 0 & 0 & 0 & 0 & 3 & 3 & 1 & 0 & 14 \\
\hline \multirow{4}{*}{$\begin{array}{l}\text { Guillermo } \\
\text { Lasso }\end{array}$} & Tuits & 36 & 2 & 2 & 35 & 20 & 4 & 24 & 33 & 46 & 16 & 24 & 18 & 24 & 19 & 9 & 11 & 323 \\
\hline & Videos & 3 & 2 & 1 & 1 & 1 & 1 & 3 & 1 & 2 & 2 & 3 & 0 & 1 & 0 & 1 & 0 & 22 \\
\hline & Fotos & 14 & 0 & 1 & 21 & 11 & 1 & 9 & 7 & 15 & 11 & 11 & 9 & 16 & 12 & 5 & 10 & 153 \\
\hline & Hashtags & 16 & 1 & 2 & 26 & 7 & 1 & 17 & 19 & 10 & 11 & 20 & 8 & 12 & 10 & 6 & 8 & 174 \\
\hline
\end{tabular}

Elaboración propia 
Ambos candidatos tuvieron regularidad en sus publicaciones diarias, aunque el segundo, @LassoGuillermo, casi duplicó su presencia en Twitter durante este periodo. Destacó el número de hashtags que utilizó para enlazar contenidos. Esta actividad mucho más frenética en las redes no le dio lugar a vencer en las elecciones y fue @Lenin el que obtuvo la Presidencia de la República de Ecuador.

\section{DATOS Y ANÁLISIS DE LOS CANDIDATOS COLOMBIANOS}

Para el análisis, también hemos elegido a los cuatro candidatos mejor situados para ocupar la Presidencia de la República de Colombia. En primer lugar, analizamos la cuenta de Iván Duque, quien tenía un total de 758 mil seguidores; la de Germán Vargas, con 809 mil seguidores; la de Gustavo Petro, con 3,37 millones de seguidores, una de las cuentas de comunicación política con más seguidores en toda Colombia; y finalmente la de Sergio Fajardo, con 1,4 millones de seguidores.

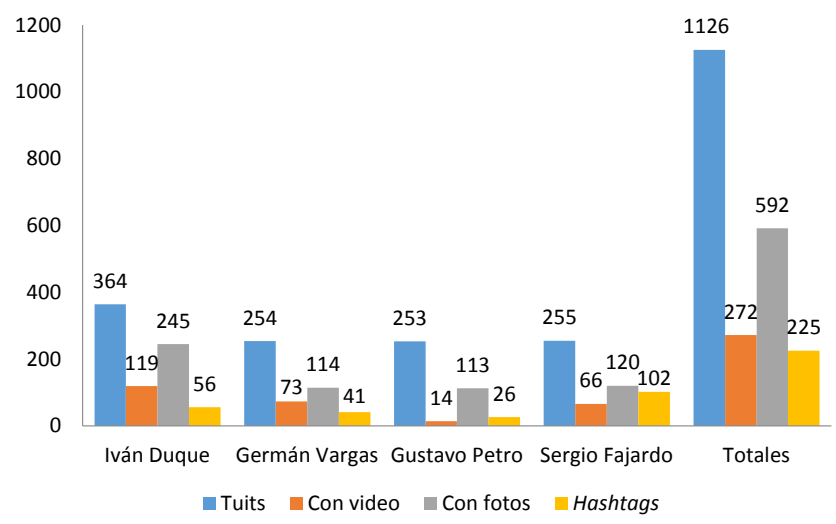

Figura 9. Tuits publicados durante las elecciones presidenciales del 2018 en Colombia (primera vuelta). Del 12 al 27 mayo del 2018 Elaboración propia

El periodo analizado para la minería de los datos comprende del 12 al 27 de mayo del 2018, intervalo de la etapa previa al proceso electoral. En la figura 9 observamos cómo los candidatos hacen un uso muy parecido de la red, incluso en el número de videos y fotografías. Destaca a @IvanDuque quien tiene una cantidad levemente superior de tuits y hace un mayor uso de audiovisuales y gráficos en sus publicaciones, aunque es @ sergio_Fajardo quien utiliza más hashtags. 


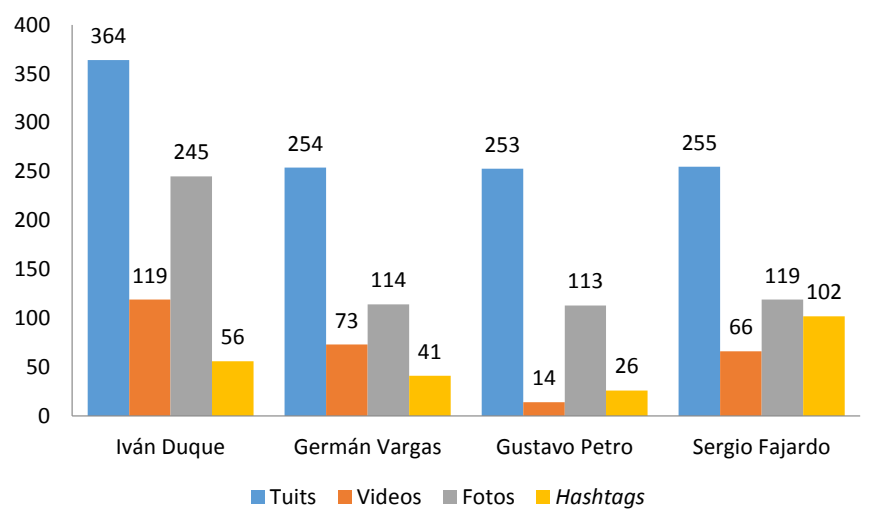

Figura 10. Actividad total en Twitter de los candidatos colombianos durante las elecciones presidenciales del 2018 (primera vuelta) Elaboración propia

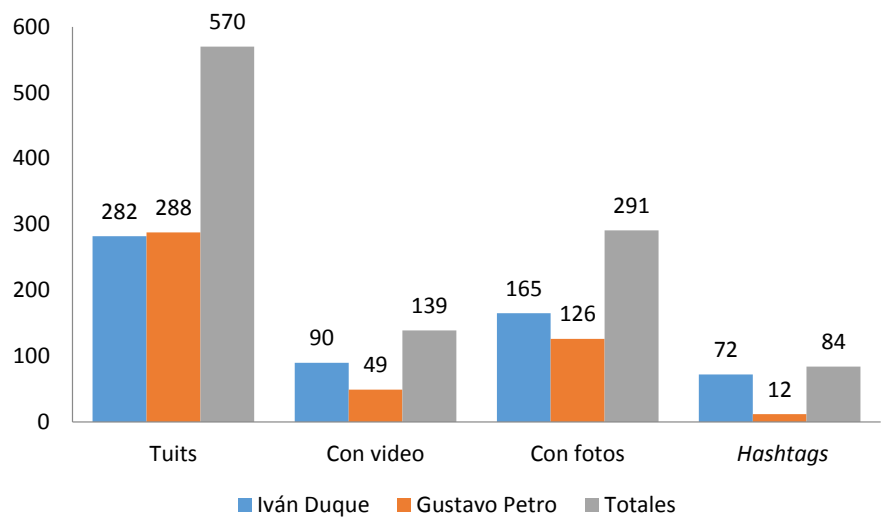

Figura 11. Tuits publicados durante las elecciones presidenciales del 2018 en Colombia (segunda vuelta). Del 2 al 17 de junio del 2018 Elaboración propia

La tabla 5 evidencia cómo el uso de Twitter en el periodo establecido fue regular para todos y se hizo más intensivo durante la última semana de la campaña electoral, en que subió el número de publicaciones. El uso de videos y fotografías también fue similar por parte de los participantes. 


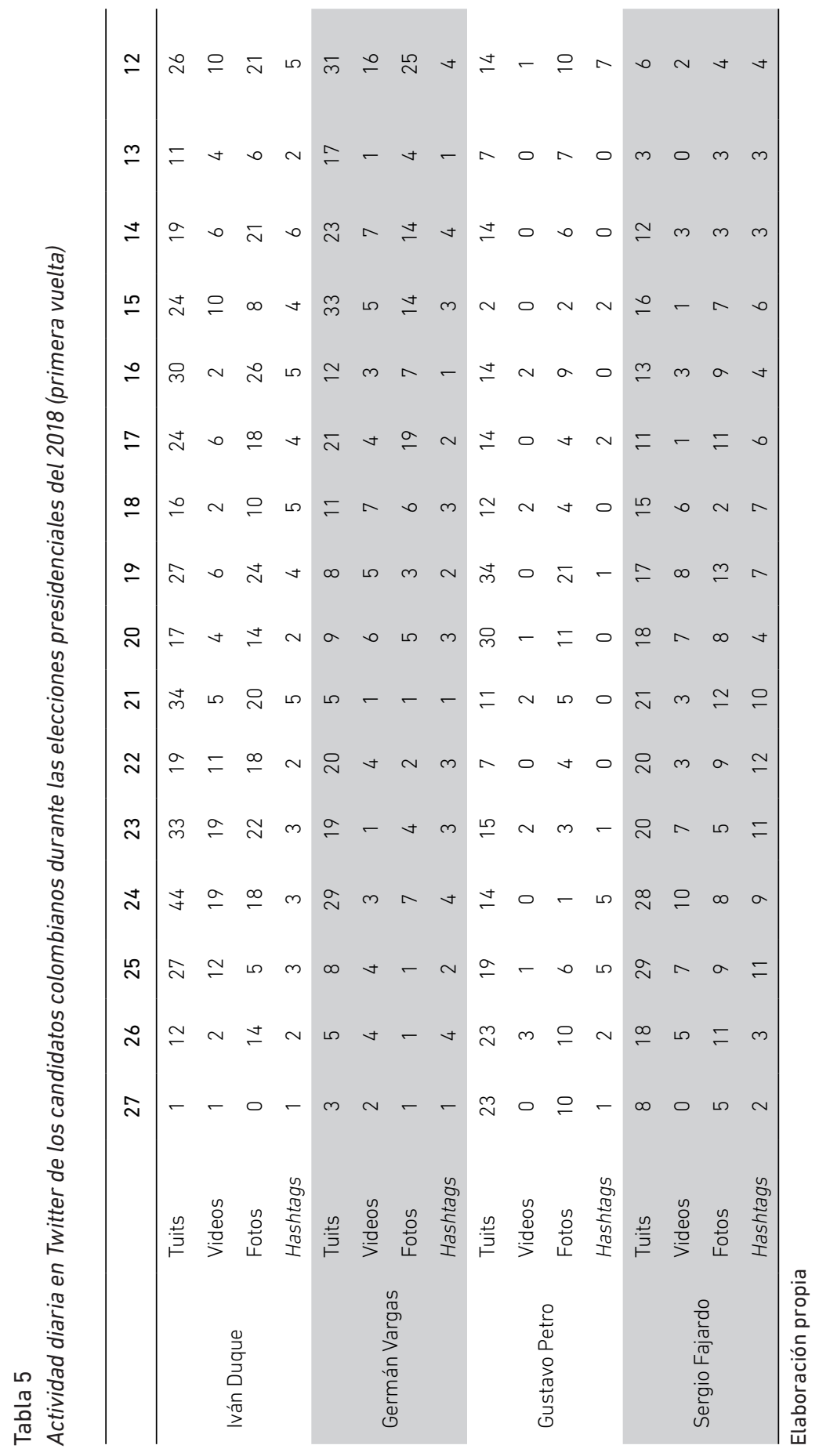




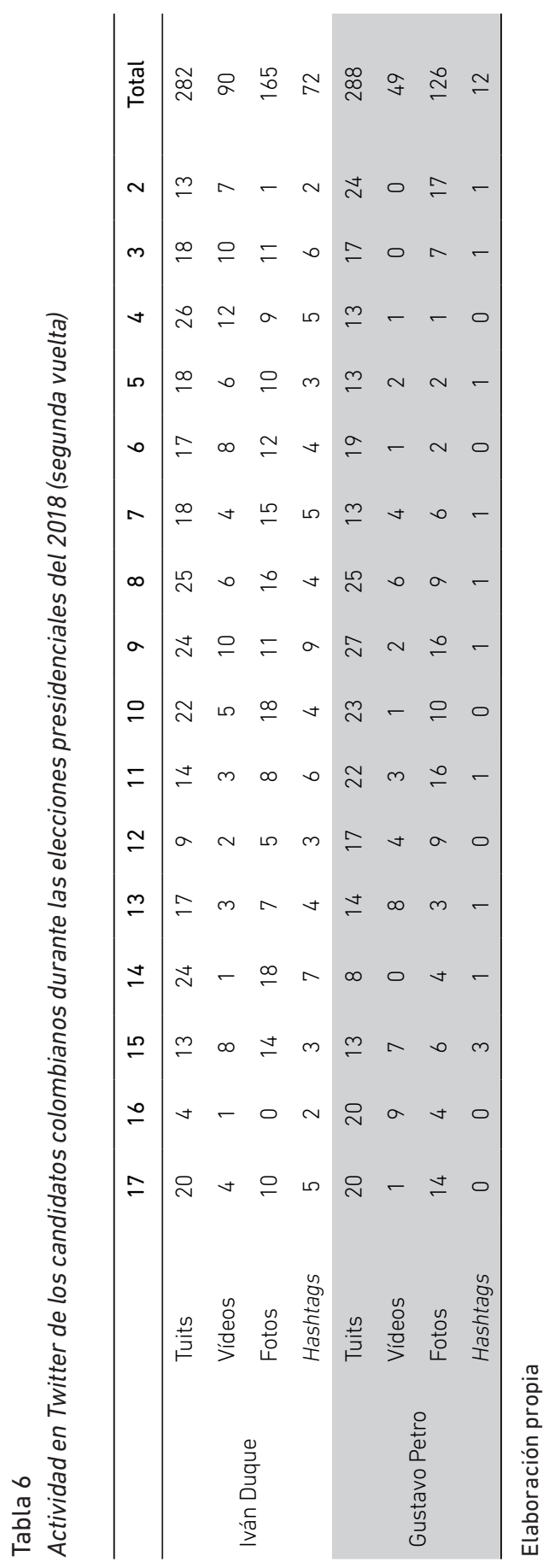


Al igual que ocurrió en Ecuador, en Colombia tampoco hubo un candidato que sumara la mayoría de los votos, por lo que, según establece la legislación colombiana, se tuvo que pasar a una segunda vuelta con los dos candidatos que más votos obtuvieron en la primera vuelta de las presidenciales. Se colige que los dos candidatos tuitearon un número similar de mensajes, aunque @lvanDuque fue el que más utilizó elementos complementarios en sus publicaciones. Durante el intervalo escogido previo a la segunda vuelta, desde el 2 al 17 de junio del 2018, se publicaron 570 tuits entre los dos candidatos, que incluyeron 139 videos y 291 fotografías.

Ambos candidatos tuvieron gran regularidad durante el proceso previo a la segunda vuelta. Se le atribuye nuevamente el uso más intenso en cuanto a medios audiovisuales y fotográficos a Duque, quien finalmente se convirtió en el presidente de la República de Colombia.

\section{DISCUSIÓN Y CONCLUSIONES}

El estudio sobre el uso de las redes sociales para la comunicación política se ha realizado en la mayoría de las ocasiones desde la perspectiva del uso tecnológico o abordando cuestiones de cantidad de información transmitida en los canales; pero creemos que también era importante analizar la comunicación política desde la perspectiva de la competencia mediática de los candidatos que utilizan dichas cuentas sociales para su comunicación política, cómo la usan y si tienen las competencias adecuadas para ello.

En cuanto a la dimensión de lenguajes, los candidatos analizados hacen un uso de forma correcta, con excepción de Paco Moncayo, de Ecuador, quien no utilizó la plataforma durante los tiempos estudiados. Pese a que en el caso de algunos candidatos colombianos se detectaron tuits con aseveraciones demonizantes hacia otros candidatos, se observa que todos tienen capacidad de interpretar y de valorar los distintos códigos de representación en los mensajes publicados durante los periodos analizados. También observamos que tienen la capacidad de expresarse mediante una amplia gama del sistema de representación y son capaces de crear y modificar mensajes ya existentes.

Respecto a la dimensión tecnológica, los candidatos comprenden el papel que desempeñan en la sociedad las tecnologías de la información y hacen uso de ellas, adecuándolas a sus objetivos comunicativos e integrando imágenes y videos desde los cuales han querido ir construyendo una conciencia de la representación de sus mensajes de captación de votantes.

Con relación a la dimensión de los procesos de interacción, se observa cómo los candidatos tuvieron durante la campaña una actitud activa en la interacción con sus posibles votantes, medios de comunicación y adversarios políticos, y eso se puede 
comprobar en la cantidad de retuits de otras cuentas que han ido integrando a la suya. Muchos han ido retuiteando sus propias publicaciones directamente o con textos que matizaban los mensajes.

En cuanto a la dimensión de los procesos de producción y difusión, por la forma en la que están diseñadas las publicaciones periódicas y constantes de todos los candidatos durante el proceso, se entiende que tenían conocimiento sobre los sistemas de producción, las técnicas de programación y los mecanismos de difusión. Se da por hecho que los candidatos tienen la capacidad de seleccionar mensajes significativos, especialmente cuando algunos de ellos llegan a una gran cantidad de personas, son capaces de transformarlos posteriormente y difundirlos en la red.

En cuanto a la dimensión de la ideología y valores, se aprecia que tienen la habilidad de buscar, organizar, priorizar y sintetizar las informaciones que quieren transmitir a los posibles votantes, y aprovechan las capacidades de Twitter para comunicar y transmitir los valores e ideologías en sus mensajes. También se observa que aprovecharon de forma adecuada el poder de Twitter para lanzar mensajes de compromiso con la ciudadanía lo que generó un acercamiento de los usuarios.

Finalmente, en cuanto a la dimensión estética, se observa cómo todos los mensajes están muy elaborados no solamente en el texto, sino en los elementos que los acompañaron (videos y fotografías), y se incrementaron los niveles de creatividad, originalidad y sensibilidad en los mismos.

Como se indicó anteriormente, no se observó una diferencia importante en las competencias mediáticas de los candidatos de los tres países. Es posible afirmar que los candidatos, excepto Moncayo, hicieron un uso muy parecido en su comunicación con sus seguidores, posibles votantes y medios de comunicación. Lo único que podemos destacar es el mayor uso que hacen los candidatos de Colombia de la herramienta Twitter en sus comunicaciones y el uso de elementos audiovisuales para mejorar sus publicaciones.

La Unesco indicaba en 1982 que "el sistema político y el sistema educativo han de reconocer la obligación de promover entre sus ciudadanos una comprensión crítica del fenómeno de la comunicación" (Unesco, 1982), y hemos podido comprobar que los candidatos analizados comprenden dicho fenómeno. Sin embargo, respecto a los cambios que está sufriendo la comunicación, tal como indica Aguaded et al. (2011), son necesarios programas educativos para la población en general, para que pueda seguir y comprender los mensajes que se transmiten, en este caso por los candidatos a las presidencias de sus gobiernos. 


\section{REFERENCIAS}

Aguaded, J. I., Ferrés, J., Díaz-Cruz, M. d. R., Pérez-Rodríguez, M. A., Sánchez-Carrero, J. y Delgado-Ponce, Á. (2011). In Grupo de Investigación Ágora de la Universidad de Huelva (Ed.), El grado de competencia mediática en la ciudadanía andaluza (Universidad de Huelva. Grupo Ágora ed.). Huelva: Grupo Comunicar.

Asamblea Constituyente (2008). Constitución de la República del Ecuador. Recuperado de https://bit.ly/2FFdsH9

Asamblea Constituyente (2009). Ley orgánica electoral. Código de la democracia. Ecuador. Recuperado de https://goo.gl/zPGKY9

Asamblea Constituyente (2013). Ley orgánica de comunicación. Recuperado de https:// bit.ly/1NNTLae

Baumgartner, J. C. y Morris, J. S. (2010). Myfacetube politics: Social networking web sites and political engagement of young adults. Social Science Computer Review, 28(1), 24-44. doi:https://doi.org/10.1177/0894439309334325

BOE. (1978). Constitución española. Recuperado de https://goo.gl/KPjuuP

BOE. (1985). Ley orgánica 5/1985, de 19 de junio, del régimen electoral general. Recuperado de https://goo.gl/CpAXyJ

Budiharto, W. y Meiliana, M. (2018). Prediction and analysis of indonesia presidential election from twitter using sentiment analysis. Journal of Big Data, 5(1). doi:https:// doi.org/10.1186/s40537-018-0164-1

Canel, M. (1999). Comunicación política: Técnicas y estrategias para la sociedad de la información (segunda ed.). Madrid: Tecnos.

Cansino, C., Calles, J. y Echeverría, M. (2016). Del Homo Videns al Homo Twitter: democracia y redes sociales. En C. Cansino, J. Calles y M. Echeverría (Eds.). Puebla: Benemérita Universidad Autónoma de Puebla.

Castells, M. (2015). Networks of outrage and hope: Social movements in the internet age John Wiley y Sons.

Consejo Nacional Electoral. Colombia. (2018). Elecciones presidenciales 2018. Recuperado de https://bit.ly/2x6pWB1

Consejo Nacional Electoral. Ecuador. (2017). Elecciones generales 2017. Recuperado de https://goo.gl/kJV4Be

Conway, B. A., Kenski, K. y Wang, D. (2015). The rise of twitter in the political campaign: Searching for intermedia agenda-setting effects in the presidential primary. 
Journal of Computer-Mediated Communication, 20(4), 363-380. https://doi. org/10.1111/jcc4.12124

Corte Constitucional. Gobierno de Colombia. (1991). Constitución política de Colombia. Recuperado de https://goo.gl/ASqRvr

Dimitrova, D. V., Shehata, A., Strömbäck, J. y Nord, L. W. (2014). The effects of digital media on political knowledge and participation in election campaigns: Evidence from panel data. Communication Research, 41(1), 95-118. https://doi. org/10.1177/0093650211426004

Eddington, S. M. (2018). The communicative constitution of hate organizations online: A semantic network analysis of "Make America great again". Social Media and Society, 4(3) https://doi.org/10.1177/2056305118790763

El Tantawi, M., Al-Ansari, A., AlSubaie, A., Fathy, A., Aly, N. M. y Mohamed, A. S. (2018). Reach of messages in a dental twitter network: Cohort study examining user popularity, communication pattern, and network structure. Journal of Medical Internet Research, 20(9). https://doi.org/10.2196/10781

European Commission. (2019). Alfabetización mediática. Recuperado de https://bit. ly/2G2QNQz

Ferrés, J. y Piscitelli, A. (2012). La competencia mediática: Propuesta articulada de dimensiones e indicadores. Comunicar, 19(38). https://doi.org/10.3916/ C38-2012-02-08

Fung, I. C., Jackson, A. M., Mullican, L. A., Blankenship, E. B., Goff, M. E., Guinn, A. J., ... Tse, Z. T. H. (2018). Contents, followers, and retweets of the centers for disease control and prevention's office of advanced molecular detection (@CDC_AMD) twitter profile: Cross-sectional study. JMIR Public Health and Surveillance, 4(2), e33-e33. https://doi.org/10.2196/publichealth.8737

García-Ruiz, R., Gozálvez, V. y Aguaded, J. (2014). La competencia mediática como reto para la educomunicación: instrumentos de evaluación. Cuadernos.Info, (35), 15-27. https://doi.org/10.7764/cdi.35.623

Guerra, M. y Jordán, V. (2010). Políticas públicas de la sociedad de la información en América Latina: ¿Una misma visión?. Recuperado de https://bit.ly/2lvemWC

Hemsley, J., Stromer-Galley, J., Semaan, B. y Tanupabrungsun, S. (2018). Tweeting to the target: Candidates' use of strategic messages and @Mentions on twitter. Journal of Information Technology and Politics, 15(1), 3-18. https://doi.org/10.1080/193316 81.2017 .1338634 
Hernández, R., Fernández, C. y Baptista, M. (2014). Metodologia de la investigacion (6. ${ }^{a}$ ed.). México D.F.: McGraw-Hill.

Ituassu, A., Lifschitz, S., Capone, L., Vaz, M. B. y Mannheimer, V. (2018). Compartilhamento de mídia e preferência eleitoral no Twitter: Uma análise de opinião pública durante as eleições de 2014 no Brasil. Palabra Clave, 21(3), 860-884. https://doi. org/10.5294/pacla.2018.21.3.9

Johnson, T. J. y Kaye, B. K. (2015). Site effects: How reliance on social media influences confidence in the government and news media. Social Science Computer Review, 33(2), 127-144. https://doi.org/10.1177/0894439314537029

Keller, T. R. y Kleinen-von Königslöw, K. (2018). Followers, spread the message! Predicting the success of swiss politicians on Facebook and Twitter. Social Media and Society, 4(1). https://doi.org/10.1177/2056305118765733

Manrique-Grisales, J., Romero, Y. S. y Fernández, A. A. (2017). Competencia mediática en Colombia: Marcos de referencia para un diagnóstico. Revista Nexus Comunicación. https://doi.org/10.25100/nc.v0i21.5904

Marín-Gutiérrez, I., Díaz-Pareja, E. y Aguaded, I. (2013). La competencia mediática en niños y jóvenes: La visión de España y Ecuador. Chasqui Revista Latinoamericana De Comunicación, (124), 41-47. Recuperado de https://bit.ly/2Xp5KsW

Martínez-Martínez, S. y Lara-Navarra, P. (2014). El big data transforma la interpretación de los medios sociales. El profesional de la información, 23(6), 575-581. https:// doi.org/10.3145/epi.2014.nov.03

Mcnair, B. (2015). An introduction to political communication (5th ed.). London and New York: Routledge. https://doi.org/10.1017/СВ09780511623806

Ministerio del Interior. Gobierno de España. (2016). Resultados electorales. Congreso. Junio 2016. Recuperado de https://goo.gl/6EXg6k

Moya, M. y Herrera, S. (2015). ¿Cómo puede contribuir Twitter a una comunicación política más avanzada? Arbor, 191(774). https://doi.org/10.3989/arbor.2015.774n4012

Narváez Montoya, A. y Romero Peña, A. C. (2017). Educación mediática y nación en Colombia: Entre el púlpito e internet. Cátedra UNESCO de Comunicación, 1-7. Recuperado de https://bit.ly/31Jgi5D

Norris, P. (2004). Political communications Harvard University. Recuperado de https://bit. ly/2M9Xa7V

Oselio, B. y Hero, A. (2016). En Osgood N., Xu K.S., Reitter D. y Lee D.(Eds.), Dynamic directed influence networks: A study of campaigns on Twitter. Springer Verlag. https://doi. org/10.1007/978-3-319-39931-7_15 
Peñaherrera León, M. (2012). Uso de TIC en escuelas públicas de Ecuador: Análisis, reflexiones y valoraciones. EDUTEC. Revista Electrónica de Tecnología Educativa, (40), a201-a201. Recuperado de https://bit.ly/2lwcNrE

Pérez-Martínez, V. M., Rodríguez González, M. D. y Tobajas Gracia, M. (2017). Movilización y participación en Twitter. Estudio de caso del hashtag \#SuperTuesday en las primarias presidenciales de EEUU 2016. Revista Latina de Comunicacion Social, 72, 679-703. https://doi.org/10.4185/RLCS-2017-1186

Prada-Espinel, O. y Romero-Rodríquez, L. (2019). Polarización y demonización en la campaña presidencial de Colombia de 2018: Análisis del comportamiento comunicacional en el Twitter de Gustavo Petro e Iván Duque. Humanidades, 9(1), 1-26. https://doi.org/10.15517/h.v9i1.35343

Registraduría Nacional del Estado Civil. (1986). Decreto 2241 de 15 de julio de 1986. Código electoral colombiano. Recuperado de https://goo.gl/ca2tLG

Rheingold, H. (2008). Using Participatory Media and Public Voice to Encourage Civic Engagement. Civic Life Online: Learning How Digital Media Can Engage Youth. En W. Lance Bennett (Ed.), The John D. and Catherine T. MacArthur Foundation Series on Digital Media and Learning. Cambridge, MA: The MIT Press. Recuperado de https://bit.ly/2ZBRGcU

Rodríguez-Andrés, R. (2018). Trump 2016: Trump 2016: ¿presidente gracias a las redes sociales? Palabra Clave, 21(3), 831-859.https://doi.org/10.5294/pacla.2018.21.3.8

Ross, A. S. y Rivers, D. J. (2018). Discursive deflection: Accusation of "Fake news" and the spread of mis- and disinformation in the tweets of president trump. Social Media and Society, 4(2). https://doi.org/10.1177/2056305118776010

Sala, J. (2016). Transformando la nación por Twitter en el modelo de la democracia líquida. Revista Transparencia \& Sociedad (4), 13-38. Recuperado de https://bit. ly/2ITmz60

Santander, P., Elórtegui, C., Ginzales, C., Allende-Cid, H. y Palma, W. (2017). Redes sociales, inteligencia computacional y predicción electoral: El caso de las primarias presidenciales de Chile 2017. Cuadernos.Info, 41, 41-46. https://doi.org/10.7764/ cdi.41.1218

Sartori, G. (1998). Homo videns. Madrid: Taurus. https://doi.org/10.2307/40184167

Schreiner, T. (2018). Information, opinion, or rumor? The role of Twitter during the post-electoral crisis in Côte d'Ivoire. Social Media and Society, 4(1). https://doi. org/10.1177/2056305118765736 
Schünemann, W. J. y Steiger, S. (2015). The net neutrality debate on Twitter. Internet Policy Review 4(4), 1-13. https://doi.org/10.14763/2015.4.394

Serrano-Puche, J., Fernández, C. y Rodríguez-Virgili, J. (2018). Información política y exposición incidental en las redes sociales: Un análisis de Argentina, Chile, España y México. Doxa Comunicación, 27, 19-42. https://doi.org/10.31921/ doxacom.n27a1

Sun, H., Ch'ng, E. y See, S. (2018). Influential spreaders in the political twitter sphere of the 2013 Malaysian general election. Industrial Management and Data Systems. https://doi.org/10.1108/IMDS-09-2017-0409

Towner, T. y Munoz, C. L. (2016). Boomers versus millennials: Online media influence on media performance and candidate evaluations. Social Sciences, 5(4). https://doi. org/10.3390/socsci5040056

Towner, T. L. y Dulio, D. A. (2012). New media and political marketing in the United States: 2012 and beyond. Journal of Political Marketing, 11(1-2), 95-119. https://doi.org/10 $.1080 / 15377857.2012 .642748$

Unesco. (1982). Declaración de Grünwald sobre la educación relativa a los medios de comunicación. Recuperado de https://goo.gl/g5×5jB

Vaccari, C. y Valeriani, A. (2018). Digital political talk and political participation: Comparing established and third wave democracies. SAGE Open, 8(2). https:// doi.org/10.1177/2158244018784986

Wang, Y., Feng, Y., Zhang, X. y Luo, J. (2017). En Osgood N., Lee D., Thomson R. y Lin Y.-R. (Eds.). Inferring follower preferences in the 2016 U.S. presidential primaries with sparse learning. Springer Verlag. https://doi.org/10.1007/978-3-319-60240-0_1

Weller, K., Bruns, A., Burgess, J., Mahrt, M. y Puschmann, C. (2014). Twitter and society. Nueva York: Peter Lang. Recuperado de https://bit.ly/2a8GWdG

Wolton, D. (1998). La comunicación política: Construcción de un modelo. En J. M. Ferry (Ed.), El nuevo espacio público. Barcelona: Gedisa. 